\title{
Isolation by ConA binding of haustoria from different rust fungi and comparison of their surface qualities
}

\author{
M. Hahn* and K. Mendgen \\ Phytopathologie, Fakultät für Biologie, Universität Konstanz, Konstanz \\ Received May 7, 1992 \\ Accepted June 30, 1992
}

\begin{abstract}
Summary. Rust haustoria isolated from infected leaf tissue strongly bind to ConA. This property was exploited to purify them by affinity chromatography on a ConA-Sepharose macrobead column. Haustoria were obtained with more than $90 \%$ purity and yields of up to $50 \%$. Binding of haustoria to the column was partially inhibited by a ConA-specific sugar, methyl $\alpha$-D-mannopyranoside. Compared to ConA, Lens culinaris agglutinin and wheat germ agglutinin were less efficient affinity ligands. Using ConA-Sepharose, rust haustoria from a variety of sources could be isolated with equal efficiency, indicating that they have similar carbohydrate surface properties. The haustoria maintained their typical shape after the isolation procedure, which suggests a rather rigid wall structure. The morphology of haustoria was characteristic both for a given species and the nuclear condition of the rust mycelium. Electron microscopy of isolated haustoria revealed an intact haustorial wall surrounded by a fibrillar layer presumably derived from the extrahaustorial matrix. The matrix thus appears to represent a layer with gel-like properties which is rich in ConA-binding carbohydrates and connected to the haustorial wall but not to the host-derived extrahaustorial membrane.
\end{abstract}

Keywords: Affinity chromatography; Biotrophy; Concanavalin A; Extrahaustorial matrix; Puccinia; Uromyces.

Abbreviations: ConA Concanavalin A; LCA Lens culinaris agglutinin; WGA wheat germ agglutinin; FITC fuorescein isothiocyanate; DAPI 4',6-diamidinophenylindol $\times 2 \mathrm{HCl}$.

\section{Introduction}

Rust fungi are plant parasites which depend on living host tissue for their growth. They invade the plant, either directly through the cuticle or through the stomates of the leaf, by forming a complex set of infection

\footnotetext{
* Correspondence and reprints: Lehrstuhl für Phytopathologie, Fakultät für Biologie, Universität Konstanz, D-W-7750 Konstanz, Federal Republic of Germany.
}

structures (Staples and Macko 1984). The parasitic mycelium differentiates haustoria within host cells. Depending of the spore type, monokaryotic or dikaryotic haustoria are produced. Monokaryotic haustoria are terminal intracellular hyphae with a septum near the site of penetration. Dikaryotic haustoria have more elaborate structures. Being connected to intercellular hyphae, they originate from haustorial mother cells and consist of a haustorial neck with a haustorial body (Harder and Chong 1984). In both types of haustoria, the cytoplasm of host and parasite remains separated by the host plasma membrane (the extrahaustorial membrane), the fungal plasma membrane and, between the membranes, the extrahaustorial matrix and the haustorial body wall. Haustoria are believed to be primarily responsible for nutrient uptake of rusts and other biotrophic fungi (Mendgen 1981). In addition, they have evolved mechanisms to live in compatible host cells for extended periods of time without eliciting plant defense responses. In incompatible interactions with host plants, resistance is usually expressed during haustorium formation (Heath 1981). Despite their crucial role for biotrophy, virtually nothing is known about physical and biochemical properties and rust haustoria. This is because they are completely enclosed by host mesophyll cells and hardly accessible to experimental manipulations.

In this paper, we describe some qualities of haustoria from different rust fungi and an efficient method for their isolation, based on their affinity to the lectin ConA. 


\section{Materials and methods \\ Cultivation of plants and inoculation}

Seeds (Table 1 ) were planted in pots containing a peat-sand mixture (L75), and cultivated in growth chambers with a daily period of 14/ $10 \mathrm{~h}$ (light/dark), at temperatures ranging from 15 to $25^{\circ} \mathrm{C}$, depending on the plant species. Primary leaves of $T$. aestivum, $H$. vulgare, and $V$. sinensis and the first 3-4 leaves of the other plants were inoculated. Inoculation with uredospores and aeciospores (Table 1) was performed by spraying as described in Fink et al. (1991), or by applying a mixture of dry spores and talcum onto the leaves using a paint brush. Basidiospore inoculation was done as described by $\mathrm{Xu}$ and Mendgen (1992). Conidia of powdery mildew were applied with a brush. After inoculation, the plants were kept dark in a moist chamber for $24 \mathrm{~h}$ before returning them to the growth chamber.

\section{Isolation of haustoria}

Preparation of the leaf homogenate

Heavily infected leaf tissue was collected 4 to 6 days after inoculation and transferred into cold deionized water. Using gloved fingers, spores and mycelium adhering to the leaf surface were removed by gently rubbing over the leaves. All subsequent steps of the preparation were performed at 0 to $4^{\circ} \mathrm{C}$. To $10 \mathrm{~g}$ of leaf tissue, $100 \mathrm{ml}$ of homogenization buffer $(0.3 \mathrm{M}$ sorbitol, $20 \mathrm{mM}$ 3-morpholinopropanesulfonic acid, $0.2 \%$ polyvinylpyrrolidone, $0.2 \% \beta$-mercaptoethanol, $0.1 \%$ bovine serum albumin, $\mathrm{pH} 7.2$ ) were added, and the material was homogenized in a Waring blender at maximum speed for 10-30s, depending on the plant. To remove the debris, the leaf homogenate was passed through nylon tissue with $20 \mu \mathrm{m}$ pore size which was supported by a funnel. The filtrate was centrifuged for $5 \mathrm{~min}$ at $5000 \mathrm{~g}$, and the pellet washed once with suspension buffer ( $0.3 \mathrm{M}$ sorbitol, $10 \mathrm{mM}$ 3-morpholinopropanesulfonic acid, $0.2 \%$ bovine serum albumin, $1 \mathrm{mM} \mathrm{CaCl}, 1 \mathrm{mM} \mathrm{MnCl}$ ). The resulting pellet, consisting mainly of chloroplasts and haustoria, was brought into suspension with approx. 1-1.5 × $10^{9}$ chloroplasts/ml (referred to as filtered homogenate).

\section{Coupling of proteins to Sepharose $6 \mathrm{MB}$}

To cyanogen bromide-activated Sepharose 6MB megabeads (Pharmacia LKB, Uppsala), protein ligands were coupled according to the protocol supplied by the manufacturer. Shortly, the Sepharose beads were washed with $1 \mathrm{mM} \mathrm{HCl}$ for $15 \mathrm{~min}$, and the protein to be coupled added at a concentration of $10 \mathrm{mg} / \mathrm{ml}$ in coupling buffer $\left(0.1 \mathrm{M} \mathrm{NaHCO}_{3}, 0.5 \mathrm{M} \mathrm{NaCl}, \mathrm{pH} 8.6\right)$. After incubation at $4^{\circ} \mathrm{C}$ overnight, the beads were washed in coupling buffer, and remaining active groups blocked with $0.5 \mathrm{M}$ glycine, $0.1 \mathrm{M} \mathrm{NaHCO}$, pH 8.3. For storage, the column was equilibrated with $0.15 \mathrm{M} \mathrm{NaCl}, 10 \mathrm{mM}$ Tris$\mathrm{HCl}, 1 \mathrm{mM} \mathrm{CaCl}_{2}, 1 \mathrm{mM} \mathrm{MnCl}, \mathrm{pH} 7.2$ containing $0.02 \%$ sodium azide.

\section{Affinity chromatography}

The filtered leaf homogenate was loaded onto a Sepharose 6MB column (usually $1 \mathrm{ml}$ bed volume) coupled to the appropriate ligand, using $350 \mu \mathrm{l}$ of suspension per $\mathrm{ml}$ of column bed volume. After migration into the column, haustoria were allowed to bind by incubation for $15 \mathrm{~min}$ without flow. To elute the particles which did not bind to the column, five void volumes of suspension buffer were layered carefully on top of the column, and the buffer flow was started by opening the tubing at the bottom of the column (15-20 drops per $\mathrm{min}$ ). Another 5-10 volumes of buffer were added as before and allowed to flow through the column until the eluate was clear. To release the haustoria (and remaining chloroplasts) which had bound to the column, 3 void volumes of buffer (without methyl $\alpha$ D-mannopyranoside) were added without flow, and the column material vigorously agitated by sucking it up and down with a blunt pipette. Immediately after the beads had sedimented, the suspension containing the enriched haustoria on top of the beads was collected. If further purification of haustoria was envisaged, the suspension was left in the column, and one or two more cycles of binding, washing and release were performed.

\section{Staining and light microscopy}

Lectin staining was performed as described by Mendgen et al. (1985), and fluorescence microscopy with a Zeiss Axioskop and a PlanNeofluar objective. Staining of the nuclei with DAPI was performed as described by Freytag and Mendgen (1991 a). Differential-interference-contrast and phase-contrast microscopy was done with a Reichert Univar microscope. Photographs were taken with Agfa ortho 25 professional film.

\section{Electron microscopy}

Haustoria were concentrated by centrifugation and immediately transferred into specimen holders with a width of $0.3 \mathrm{~mm}$. Samples were high pressure frozen with the HPM 010 instrument (Balzers Union, Liechtenstein) (Mendgen et al. 1991). Freeze substitution was performed with acetone containing $4 \%$ osmic acid for $80 \mathrm{~h}$ at $-90^{\circ} \mathrm{C}$, followed by a gradual temperature increase to $-45^{\circ} \mathrm{C}$ (at $3^{\circ} \mathrm{C} / \mathrm{h}$ ), and then to $+10^{\circ} \mathrm{C}$ (at $\left.10^{\circ} \mathrm{C} / \mathrm{h}\right)$. Embedding occurred in epon-araldite and sections were produced with a Reichert Ultracut $\mathrm{E}$ microtome. The sections were stained with uranylacetate and lead ci-

Table 1. Plant cultivars and fungal isolates used in this work

\begin{tabular}{|c|c|c|}
\hline Host & Pathogen & Source \\
\hline Vicia faba cv. Con Amore & Uromyces viciae-fabae race $\mathrm{I}_{2}$ & Deising et al. (1991) \\
\hline $\begin{array}{l}\text { Vigna sinensis (Torner) Savi. } \\
\text { cv. California Blackeye }\end{array}$ & Uromyces vignae Barcl. race CPR1 & Chen and Heath (1990) \\
\hline Triticum aestivum L. cv. Ural & Puccinia graminis (Pers.) f. sp. tritici Eriks. \& Henn. race R32 & H. J. Reisener, Aachen, FRG \\
\hline Zea mays L. cv. Mutin & Puccinia sorghi Schwein. & own laboratory \\
\hline Hordeum vulgare L. cv. Proctor & Erysiphe graminis f. sp. hordei race A1-1 & Mendgen and Nass (1988) \\
\hline Trichosanthes cucumerina $\mathrm{L}$. & Sphaerotheca fuliginea $\mathrm{L}$. & W. Kabsch, Kiel, FRG \\
\hline
\end{tabular}


trate. Micrographs were taken with a Hitachi $\mathrm{H} 7000$ electron microscope, operating at $50 \mathrm{kV}$ and $75 \mathrm{kV}$.

\section{Results}

Strategy for the isolation of rust haustoria

Vicia faba leaves infected with Uromyces viciae-fabae uredospores were homogenized in a blender and passed through a $20 \mu \mathrm{m}$ mesh. The filtration step effectively removed plant debris as well as most of the intercellular hyphae. Upon microscopic examination, the filtered homogenate consisted mainly of chloroplasts and haustoria (approximate ratio 100:1, depending on lesion density), along with smaller particles, such as starch grains and mitochondria. When the filtered homogenate was incubated with FITC-labeled ConA, intense staining of haustorial surfaces was observed with a fluorescence microscope. No binding of ConA to chloroplasts was visible, but due to strong autofluorescence of these organelles, no definite conclusion was possible. These observations led to the concept of using ConA as a ligand for the separation of haustoria from contaminant particles by affinity chromatography. As a column matrix, Sepharose $6 \mathrm{MB}$ was chosen, consisting of beads sufficiently large to allow free flow of cellular particles.

\section{Binding specificity and performance of the affinity column}

Starting with the filtered homogenate, about 30 fold enrichment of haustoria was achieved after one cycle

Table 2. Inhibition of the affinity column enrichment of $U$. viciaefabae haustoria by methyl $\alpha-D$-mannopyranoside and free ConA

\begin{tabular}{lc}
\hline Treatment & Factor of enrichment \\
\hline Control & $32.1 \pm 10.1$ \\
ConA & $6.6 \pm 2.6$ \\
$\alpha-M e t h y l-m a n n o s i d e$ & $5.5 \pm 1.1$ \\
\hline
\end{tabular}

For the experiments, $350 \mu$ of filtered homogenate from infected leaves and columns with $1 \mathrm{ml}$ bed volume were used. One cycle of binding and release was performed. The factor of enrichment was calculated after determining the percentage of haustoria (relative to total number of particles) in the suspension before and after passage through the column. Control: The enrichment was done as described in Materials and methods. ConA: The filtered homogenate was prein" cubated in suspension buffer containing $10 \mathrm{mg} / \mathrm{ml}$ ConA for $20 \mathrm{~min}$ before loading it onto the column. $\alpha$-Methyl mannoside: The column was preincubated with suspension buffer containing $0.2 \mathrm{M}$ methyl $\alpha$-D-mannopyranoside for $20 \mathrm{~min}$ before loading the filtered homogenate onto the column. Elution was done with suspension buffer containing $0.2 \mathrm{M}$ methyl $\alpha-\mathrm{D}$-mannopyranoside. The values represent the means of three experiments, with standard deviations of binding and release to ConA-Sepharose 6MB (Table 2, control). The effectiveness of the column was reduced about sixfold after preincubation with $0.2 \mathrm{M}$ methyl $a$-D-mannopyranoside, a sugar specifically bound by ConA. Similarly, the performance of the column was inhibited when the homogenate was incubated with free ConA before applying it to the column (Table 2). Once they had bound to the column, however, the haustoria could not be released by elution with methyl $\alpha$-D-mannopyranoside. Therefore, the haustoria were released mechanically, which was achieved with an efficiency of more than $80 \%$.

A comparison was made between ConA and two other lectins, with regard to their ability to serve as affinity ligands for haustoria. LCA binds $\alpha$-mannoside and $\alpha$ glucoside residues, very similar to ConA, whereas WGA is specific for chitin and its oligomers. By far the highest enrichment and recovery of haustoria was achieved with ConA as a ligand (Table 3). Bovine serum

Table 3. Enrichment of U. viciae-fabae haustoria by different protein ligands coupled to Sepharose $6 \mathrm{MB}$

\begin{tabular}{lrr}
\hline Ligand & $\begin{array}{c}\text { Factor of } \\
\text { enrichment }\end{array}$ & Yield (\%) \\
\hline ConA & $24.7 \pm 8.2$ & $53 \pm 17.0$ \\
LCA & $7.4 \pm 4.0$ & $21.7 \pm 1.5$ \\
WGA & $5.7 \pm 2.5$ & $18.2 \pm 7.5$ \\
Bovine serum albumin & $11.0 \pm 4.9$ & $13.8 \pm 6.7$ \\
Glucosamine & $3.6 \pm 2.4$ & $6.3 \pm 3.4$ \\
\hline
\end{tabular}

As a non-ligand control, cyanogen bromide-activated Sepharose $6 \mathrm{MB}$ was reacted with $0.5 \mathrm{M}$ glucosamine. The data are the means of five (LCA: three) experiments done in parallel, with standard deviations

Table 4. Three-step enrichment of haustoria from $U$. viciae-fabae infected Vicia faba leaves with ConA-Sepharose $6 \mathrm{MB}$

\begin{tabular}{llc}
\hline & $\begin{array}{l}\% \text { of haustoria } \\
\text { in suspension }\end{array}$ & $\begin{array}{l}\% \text { recovery of } \\
\text { haustoria }\end{array}$ \\
\hline Homogenate & 1.0 & $(100)$ \\
after 1. cycle & 29.2 & 71.5 \\
after 2. cycle & 79.0 & 41.9 \\
after 3. cycle & 95.4 & 30.3 \\
\hline
\end{tabular}

$350 \mu$ of a filtered homogenate containing $4.6 \times 10^{8}$ chloroplasts were loaded onto a $1 \mathrm{ml}$ column. Haustorial counts were made relative to the total number of particles observed in the suspensions. Factors of enrichment were identical to the percentage of haustoria in this experiment 
albumin, which was included as a non-lectin protein, also gave some enrichment, albeit with low recoveries. With Sepharose coupled to glucosamine, little enrichment of haustoria was obtained.

Depending on density and age of the colonies in rustinfected leaves, 0.3 to $2 \%$ of the microscopically visible particles (chloroplasts and haustoria) in the filtered homogenate were haustoria. In order to obtain haustoria with at least $90 \%$ purity, two or three rounds of enrichment on ConA-Sepharose $6 \mathrm{MB}$ were usually required. An example of a three-step purification of $U$. viciae-fabae haustoria is shown in Table 4.

\section{Affinity isolation of rust haustoria from diverse sources}

Next, we tested whether affinity chromatography on ConA-Sepharose $6 \mathrm{MB}$ would be of general use for the isolation of haustoria from diverse species of biotrophic fungi.

Rust haustoria from $U$. viciae-fabae, Puccinia graminis, and $P$. sorghi were bound by the column with equal efficiency, with respect to enrichment and recovery (Table 5). $U$. vignae, a macrocyclic rust which completes its life cycle on cowpea, produces five spore types; three, namely uredospores, aeciospores (both dikaryotic), and basidiospores (haploid) are infectious and give rise to biotrophic mycelia and the respective haustoria. When cowpea leaves were incolated with each of these spores, the haustoria resulting from the different infections could be enriched by ConA-Sepharose with similar efficiencies (Table 5).

In contrast to rust haustoria, however, haustoria from the powdery mildews Sphaerotheca fuliginea (Table 5), Erysiphe pisi and E. graminis f. sp. hordei (not shown) bound only weakly to the column.

\section{Light microscopy of isolated haustoria}

Most haustoria from dikaryotic infections had kept their neck and the presence of neckbands was detectable (Figs. 1, 2, and 8). Species-specific morphological features were evident. Whereas (uredospore-derived) haustoria of the broad bean rust $U$. viciae-fabae (Fig. 2) and the cowpea rust $U$. vignae(Fig. 3) exhibited an oval or irregularly lobed shape, those of the cereal rusts, $P$. graminis (Fig. 1) and P. sorghi (Fig. 5), were more elongated. $P$. graminis haustoria only rarely formed lobes, whereas $P$. sorghi often produced fingerlike haustorial bodies with two or three fingers radiating from the neck region. $U$. vignae haustoria from aeciospore infection were indistinguishable from those obtained after uredospore infection (not shown).

Table 5. Enrichment of haustoria from different fungal species and spore types by ConA-Sepharose 6MB

\begin{tabular}{llcc}
\hline Fungal pathogen (spore type) & Host plant & $\begin{array}{l}\text { Factor of } \\
\text { enrichment }\end{array}$ \\
\hline Uromyces viciae-fabae I $_{2}$ (uredospores) & Vicia faba cv. Con Amore & $32.1 \pm 10.1$ & $63 \pm 13$ \\
U. vignae CPR1 (uredospores) & Vigna sinensis cv. California Blackeye & $40.1 \pm 13.3$ & $52 \pm 25$ \\
U vignae CPR1 (aeciospores) & V. sinensis cv. California Blackeye & $42.2 \pm 23.6$ & $46 \pm 6$ \\
U. vignae CPR1 (basidiospores) & V. sinensis cv. California Blackeye & $40.4 \pm 14.1$ & $63 \pm 15$ \\
Puccinia graminis f. sp. tritici R32 (uredospores) & Triticum aestivum cv. Ural & $31.9 \pm 18.7$ & $44 \pm 4$ \\
Puccinia sorghi (uredospores) & Zea mays cv. Mutin & $23.2 \pm 9.4$ & $32 \pm 15$ \\
Sphaerotheca fuliginea (conidia) & Trichosanthes cuctumerina & $3.6 \pm 1.2$ \\
\hline
\end{tabular}

Data are the means of at least three experiments, with standard deviations

n.d. Not determined

Figs. 1-5. Light micrographs of enriched haustoria. Bars: $25 \mu \mathrm{m}$

Fig. 1. $P$. graminis f. sp. tritici. Phase-contrast

Fig. 2. $U$. viciae-fabae. Differential-interference-contrast

Fig. 3. $U$, vignae (dikaryotic). Staining with DAPI and Calcofluor, showing two nuclei (photograph by M. Stark)

Fig. 4. $U$. vignae (monokaryotic). a-c Differential-interference-contrast ( $s$ septum). d Staining with DAPI and Calcofluor, showing a single nucleus

Fig. 5. $P$. sorghi. a Staining with $0.1 \mathrm{M}$ FITC-ConA for $30 \mathrm{~min}$. b Staining with $0.1 \mathrm{M}$ FITC-ConA and $0.2 \mathrm{M}$ methyl $\alpha$-D-mannopyranoside, preincubated for $30 \mathrm{~min}$. $\mathrm{c}$ Staining with $0.1 \mathrm{M}$ FITC-WGA for $30 \mathrm{~min}$ 


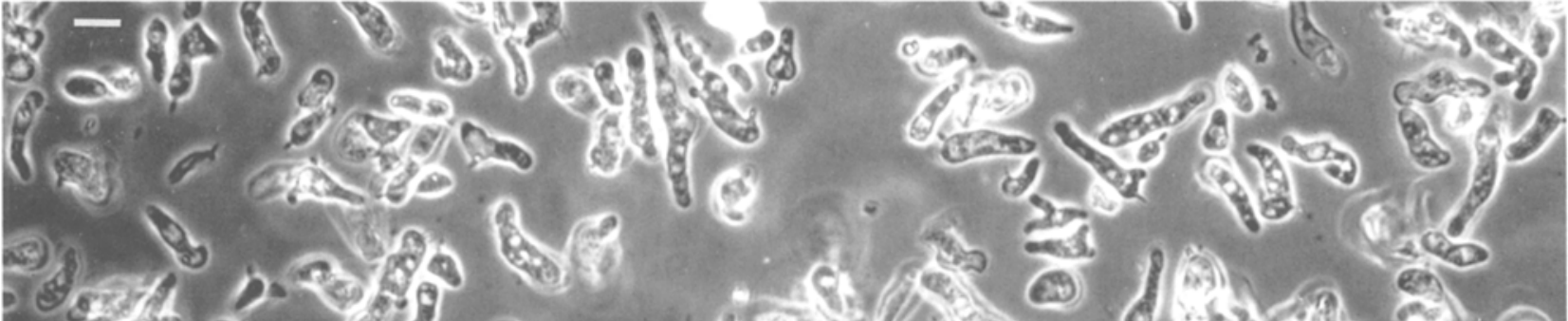

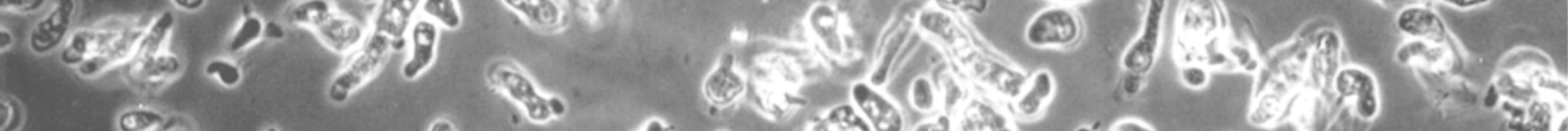

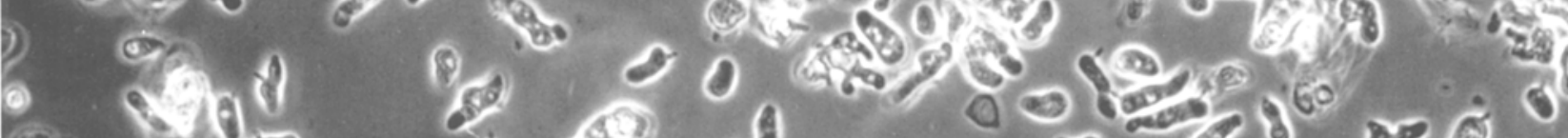
(2)

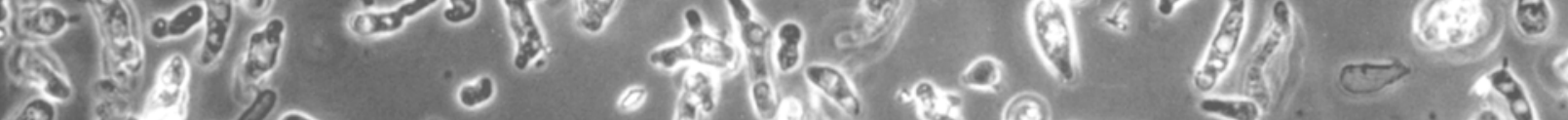

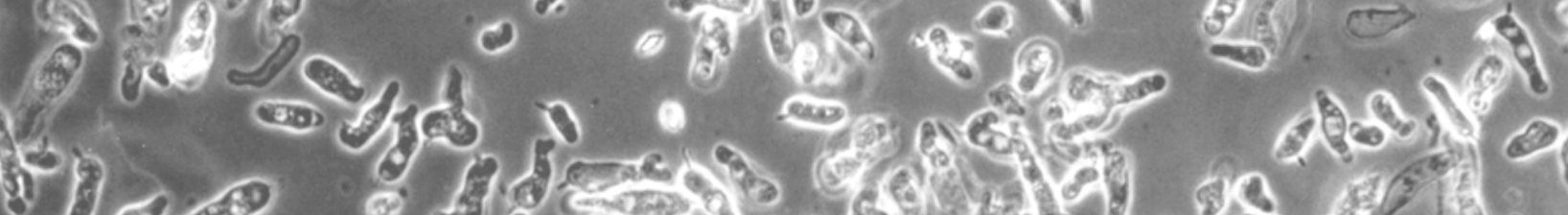

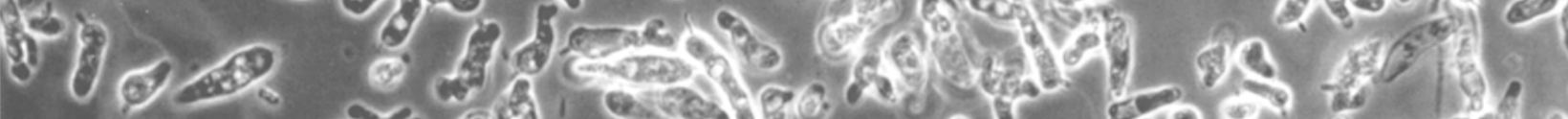

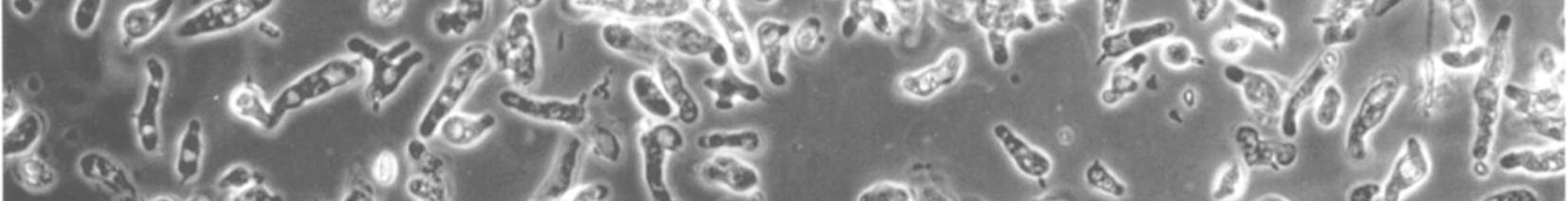

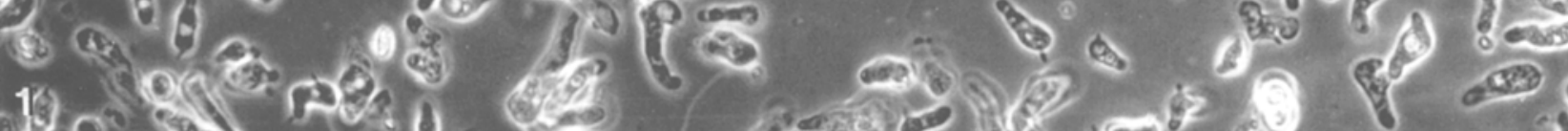
(4)

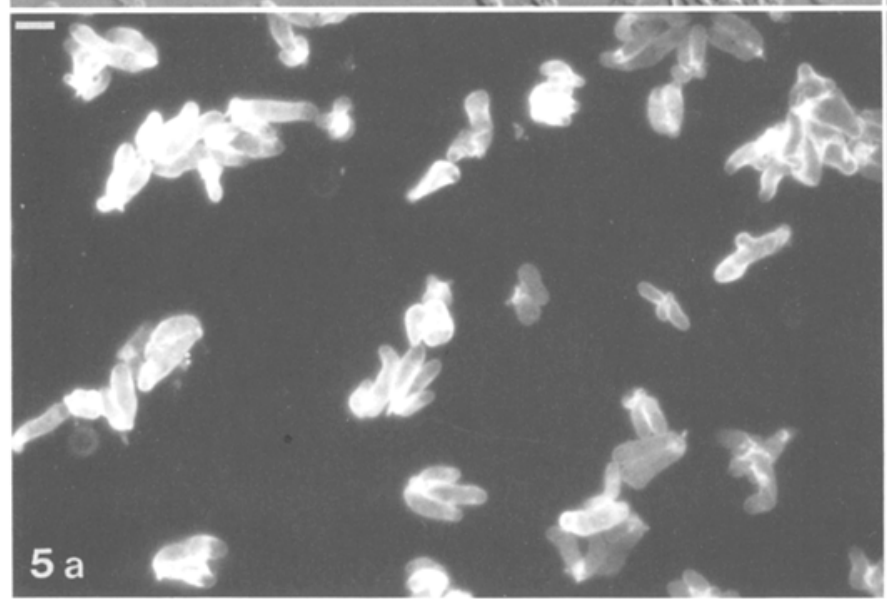

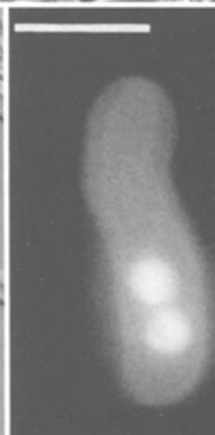

3

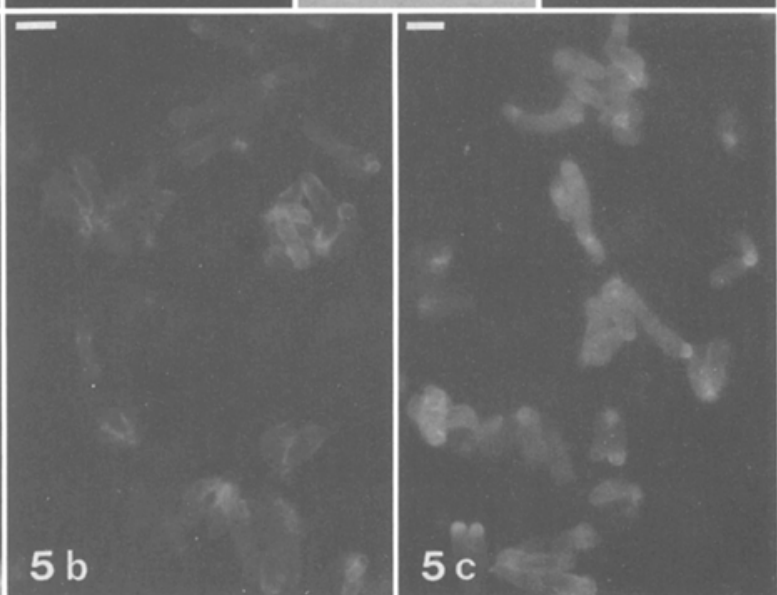



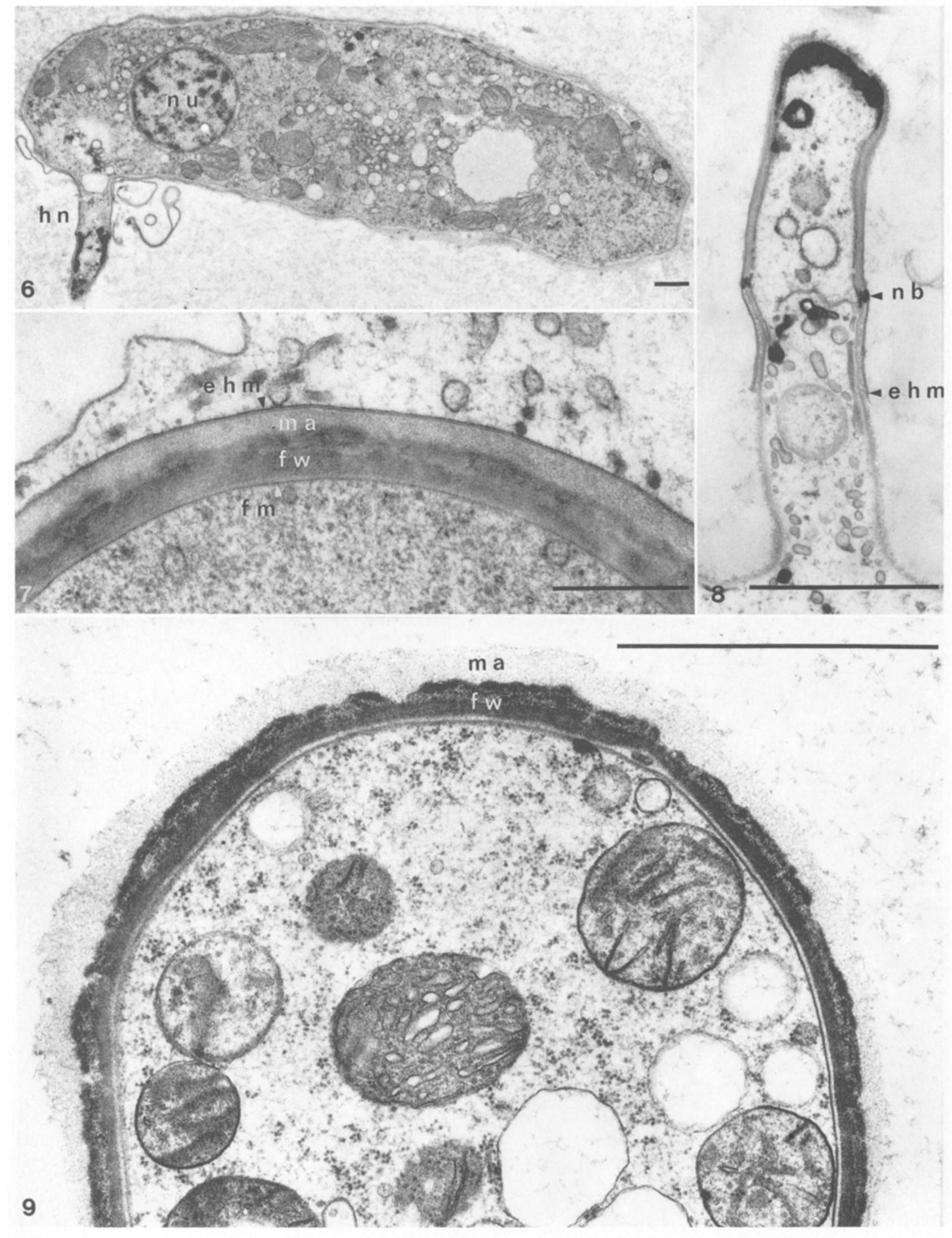
Basidiospore-derived (monokaryotic) haustoria have a simple tube-like morphology in the plant cell, resembling terminal hyphae (Chong et al. 1981). After isolation, they were observed as similar structures, being tapered in the "neck" region and club-like or sometimes branched at their distal ends (Fig. 4 a-d). Often, a septum was observed which prevented leaking of cytoplasm from these haustoria (Fig. 4 b).

DAPI-staining of haustoria from $U$. vignae revealed up to two nuclei in uredospore-derived haustoria (Fig. 3), but never more than one nucleus in basidiospore-derived haustoria (Fig. 4 d).

When isolated haustoria were stained with FITCConA, strong surface fluorescence was observed (for $P$. sorghi, see Fig. 5a). Preincubation of the labelled ConA with methyl $\alpha$-D-mannopyranoside strongly, but not completely suppressed fluorescence (Fig. 5 b). In contrast, FITC-WGA (Fig. $5 \mathrm{c}$ ) and FITC-LCA (not shown) gave only a moderate fluorescence, which was abolished by the respective binding sugars, chitin hydrolysate and methyl $\alpha$-D-mannopyranoside. Similar results of the lectin stainings were obtained with all types of haustoria.

\section{Ultrastructure of isolated haustoria}

Electron microscopy revealed that isolated haustoria had lost the extrahaustorial membrane around the haustorial body (Figs. 6 and 9). The haustorial wall was well preserved; it was covered by a fibrillar layer representing the extrahaustorial matrix. Compared to the extrahaustorial matrix observed in planta (Fig. 7), it appeared swollen and partially removed (Fig. 9). In a few instances remnants of the extrahaustorial membrane still covered the fibrillar layer (not shown).

The haustorial neck wall was well preserved (Fig. 8). Here, parts of the extrahaustorial membrane remained connected in the zone of the neckband. A mixture of dark material and fungal membranes had occluded the neck. Most haustoria exhibited more or less extensive vacuolisation, and endomembranes were undulated or even vesiculated. The fungal plasma membrane was not closely appressed to the haustorial wall. Vesicles were found in this zone (Figs. 6 and 9).

\section{Discussion}

We have isolated haustoria from different rust fungi growing in the tissue of their respective host plant. This was achieved by affinity chromatography on a macrobead Sepharose column which has been developed for the separation of blood cells according to their carbohydrate surface composition (Sharpe 1988). Using this matrix with ConA as ligand, haustoria are efficiently separated from particulate contaminants present in the leaf homogenate, predominantly chloroplasts. Although hyphal fragments were observed to bind to the affinity column too, most of them were removed by the initial filtration step.

The nature of haustorial binding to ConA was investigated by two different approaches. Enrichment of haustoria by ConA-Sepharose was strongly reduced, but not completely abolished, by preincubation of the column with a ConA-specific sugar, methyl $\alpha$-D-mannopyranoside (Table 2). When two other lectins, LCA and WGA, were coupled to the Sepharose column, much lower enrichment of haustoria was achieved than with ConA (Table 3). Similar results were obtained when isolated haustoria were incubated with FITClabelled lectins: Again, the strongest binding was observed with ConA. These data indicate that binding of haustoria to ConA consists of a carbohydrate-specific and a nonspecific component. The carbohydrate-specific binding is most likely due to the presence on the haustorial surface of $\alpha$-linked mannoside residues, which are common in glycoproteins and wall polysaccharides of rust fungi (Kim et al. 1982). The nonspecific component is responsible for the residual binding observed in the presence of methyl $\alpha$-D-mannopyranoside, and for the binding which prevents elution of haustoria from the affinity column with methyl $\alpha$-Dmannopyranoside. In addition, it might explain the remarkable difference of ConA and LCA in their affinity to haustoria, in light of the very similar sugar

Figs. 6-8. Electron micrographs of haustoria from $U$, viciae-fabae. Bars: $1 \mu \mathrm{m}$

Fig. 6. Mature haustorium shortly after isolation. $n u$ Nucleus; $h n$ haustorial neck

Fig. 7. The interface between host and parasite within the plant cell, showing the fungal plasma membrane $(\mathrm{fm})$, the fungal wall $(\mathrm{fw})$, the extrahaustorial matrix (ma) and the extrahaustorial membrane (ehm)

Fig. 8. The haustorial neck with the neck band $(n b)$ and some remnants of the extrahaustorial membrane (ehm). A plug of dark material is visible at the site of rupture from the haustorial mother cell

Fig. 9. The "interface" of isolated haustoria showing the intact fungal wall $(\mathrm{fw})$ and the fibrillar layer of the extrahaustorial matrix (ma) 
specificity of these lectins. The polypeptide sequence of ConA was found to contain stretches of hydrophobic amino acids in the $\mathrm{C}$-terminal region, which could be involved in the nonspecific binding of the lectin to haustoria (Becker et al. 1976). Since the extrahaustorial membrane largely was lost during isolation of the haustoria from leaf tissue, it is obvious that the lectins bind to carbohydrates from the haustorial wall and the matrix.

Haustoria from different biotrophic fungi were tested for their affinity to the ConA column. Efficient enrichment of haustoria from rust fungi was achieved, irrespective of the species and of the spore types used for infection. Similar to the results with the affinity columns were those obtained after staining of isolated haustoria with FITC-labelled lectins: All haustoria bound strongly to ConA, but significantly weaker to WGA and LCA. This means that rust haustoria share a remarkable degree of similarity in their carbohydrate surface properties, in particular with regard to the presence of binding sites for ConA. In contrast to rust haustoria, powdery mildew haustoria bound only weakly to ConA-Sepharose. After their isolation, haustoria from pea powdery mildew usually remain enclosed by the extrahaustorial membrane (Gil and Gay 1977). Staining of this membrane and of the underlying matrix with ConA-FITC was found to be low or absent (Chard and Gay 1984). This might explain the weak binding of powdery mildew haustoria to the ConA column.

The morphology and size of isolated rust haustoria exhibited the typical variability of haustoria of different age. In addition, haustoria from each rust species revealed quite distinctive features, such as the bi- or trifurcate shape of haustoria from $P$. sorghi. This demonstrates that the haustorial wall represents a rather rigid structure which maintains the morphology of haustoria in the absence of surrounding host cytoplasm. Similarly, monokaryotic haustoria kept their typical structure which differentiates them from dikaryotic haustoria. The morphology of isolated haustoria might therefore be useful as a characteristic for the identification of rust fungi in diseased leaf tissue. Electron microscopy of isolated haustoria revealed some damage due to the osmotic shock during shearing off from the haustorial mother cell. Nevertheless, many haustoria were found which had maintained their cytoplasmic contents largely intact. In those cases, the haustorial neck was sealed by dark staining aggregates, which prevented efflux of fungal cytoplasm. Whereas the haustorial wall remained largely intact, the matrix surrounding the wall appeared to be swollen and may have been partially removed. The fibrillar nature of the matrix has been already observed by Coffey and Allen (1983). Interestingly, haustoria formed in the absence of a host plant were also shown to develop a fibrillar layer extending from the wall which exhibits affinity to ConA (Heath 1989).

From these observations, together with the lectin binding data, we propose that the extrahaustorial matrix of rust haustoria consists of a gel-like layer rich in $\alpha$ mannosidic (or $a$-glucosidic) carbohydrates. Since these ConA-binding carbohydrates are not washed away during the isolation procedure, they are likely part of the loose network which is found to be attached to the walls of isolated haustoria. The physical connection of matrix components to the haustorial wall (and not to the extrahaustorial membrane!) is intriguing in light of the location of the extrahaustorial matrix between parasite and host tissue. Isolated haustoria could be valuable tools for studying the unresolved question regarding the contributions of both organisms to the formation of the matrix (O'Connell et al. 1986). Protocols for the isolation of fungal haustoria have been described so far only for powdery mildews, but the yields obtained were low (Gil and Gay 1977). Nevertheless, isolated mildew haustoria have been used successfully for the generation of a monoclonal antibody specific for the haustorial plasma membrane (Mackie et al. 1991). Taking advantage of the affinity of rust haustoria to ConA, we have developed a powerful method for their isolation in large scales. Starting with $20 \mathrm{~g}$ of broad bean leaves infected with $U$. viciaefabae, yields of up to $5 \times 10^{7}$ haustoria were obtained. This is ten times more than the yields obtained with pea powdery mildew haustoria (Mackie et al. 1991). The affinity isolation can be performed in less than two hours, and the column can be used several times. Despite the damage suffered by haustoria during isolation, their molecular constituents do not seem to be subjected to major degradation. In preliminary studies, proteins of isolated haustoria were found to remain largely intact. We have started experiments to use isolated haustoria for the generation of molecular probes in order to study haustorial function in planta.

\section{Acknowledgements}

We thank Annette Klink for skilled assistance with the photographic work and Martina Stark for help with basidio- and aeciospore infections. This research was supported by a grant from the Deutsche Forschungsgemeinschaft (Me 523/14-1). 


\section{References}

Becker JW, Cunningham BA, Reeke Jr. GN, Wang JL, Edelman GM (1976) The molecular structure of ConA. In: Bittiger $\mathrm{H}$, Schnebli HP (eds) Concanavalin A as a tool. Wiley, London, pp $33-54$

Chard JM, Gay JL (1984) Characterization of the parasitic interface between Erysiphe pisi and Pisum sativum using fluorescent probes. Physiol Plant Pathol 25: 259-276

Chen CY, Heath MC (1990) Cultivar-specific induction of necrosis by exudates from basidiospore germlings of the cowpea rust fungus. Physiol Mol Plant Pathol 37: 169-177

Chong J, Harder DE, Rohringer R (1981) Ontogeny of mono- and dikaryotic rust haustoria: cytochemical and ultrastructural studies. Phytopathology 71: 975-983

- - - (1986) Cytochemical studies on Puccinia graminis f. sp. tritici in a compatible wheat host. II. Haustorium mother cell walls at the host cell penetration site, haustorial walls, and the extrahaustorial matrix. Can J Bot 64: 2561-2575

Coffey MD, Allen FHE (1983) A quantitative histological and ultrastructural analysis of interactions between the flax rust nearisogenic host lines varying in their degree of incompatibility. Can J Bot 61: 1831-1850

Deising H, Jungblut PR, Mendgen K (1991) Differentiation-related proteins of the broad bean rust fungus Uromyces viciae-fabae, as revealed by high resolution two-dimensional polyacrylamide gel electrophoresis. Atch Microbiol 155: 191-198

Fink W, Haug M, Deising H, Mendgen K (1991) Early defence responses of cowpea (Vigna sinensis L.) induced by non-pathogenic rust fungi. Planta 185: 246-254

Freytag S, Mendgen K (1991 a) Surface carbohydrates and cell wall structure of in vitro induced uredospore infection structures of Uromyces viciae-fabae before and after treatment with enzymes and alkali. Protoplasma 161: 94-103

- - (1991 b) Carbohydrates on the surface of urediniospore- and basidiospore-derived infection structures of heteroecious and autoecious rust fungi. New Phytol 119: 527-534

Gil F, Gay JL (1977) Ultrastructural and physiological properties of the host interfacial components of haustoria of Erysiphe pisi in vivo and in vitro. Physiol Plant Pathol 10: 1-12

Harder DE, Chong J (1984) Structure and physiology of haustoria.
In: Bushnell WR, Roelfs AR (eds) The cereal rusts, vol 1, origins, specificity, structure, and physiology. Academic Press, Orlando, pp $431-476$

Heath MC (1981) Resistance of plants to rust infection. Phytopathology 71: 971-974

Kim WK, Rohringer $R$, Chong J (1982) Sugar and amino acid composition of macromolecular constituents released from walls of uredosporelings of Puccinia graminis tritici. Can J Plant Pathol 4: $317-327$

Mackie AJ, Roberts AM, Callow JA, Green JR (1991) Molecular differentiation in pea powdery-mildew haustoria. Identification of a $62-\mathrm{kDa}$ N-linked glycoprotein unique to the haustorial plasma membrane. Planta 183: $399-408$

Mendgen K (1981) Nutrient uptake in rust fungi. Phytopathology 71: 983-989

- Nass P (1988) The activity of powdery-mildew haustoria after feeding the host cells with different sugars, as measured with a potentiometric cyanine dye. Planta 174: 283-288

- Lange M, Bretschneider K (1985) Quantitative estimation of the surface carbohydrates on the infection structures of rust fungi with enzymes and lectins. Arch Microbiol 140: 307-311

- Welter K, Scheffold F, Knauf-Beiter G (1991) High pressure freezing of rust infected plant leaves. In: Mendgen $\mathrm{K}$, Lesemann DE (eds) Electron microscopy of plant pathogens. Springer, Berlin Heidelberg New York Tokyo, pp 31-42

O'Connell RJ, Bailey JA, Vose JR, Lamb CJ (1986) Immunogold labelling of fungal antigens in cells of $P$ haseolus vulgaris infected by Colletotrichum lindemuthianum. Physiol Mol Plant Pathol 28 : 99-105

Sharpe PT (1988) Affinity chromatography. In: Burdon RH, van Knippenberg PH (eds) Laboratory techniques in biochemistry and molecular biology, vol 18, Methods in cell separation. Elsevier, Amsterdam, pp 159-186

Staples RC, Macko V (1984) Germination of urediospores and differentiation of infection structures. In: Bushnell WR, Roelfs AP (eds) The cereal rusts, vol 1, origins, specificity, structure, and physiology. Academic Press, Orlando, pp 255-289

Xu H, Mendgen K (1992) Early events in living epidermal cells of cowpea and broad bean during infection with basidiospores of the cowpea rust fungus. Can J Bot 69: 2279-2285 